DOI: 10.24234/wisdom.v14i1.315

Irina UTIUZH, Natalia SPYTSIA, Alla SINITSYNA, Natella PAVLENKO

\title{
SCIENTIFIC AND EDUCATIONAL TECHNOLOGIES IN HUMAN CAPITAL FORMATION
}

\begin{abstract}
The article deals with a constructive role of socio-humanitarian and philosophical knowledge in the system of natural science structures. It is proved that the relevance of socio-humanities and philosophy is a response to the challenges of the modern technology-based civilization, where exact and natural sciences call for the revival of a philosophic component in the education system and science. In the article, the main cause-and-effect relations that have resulted in modern societies in demand for revival of philosophic and socio-humanitarian knowledge in science and education are revealed. A new paradigm for the development of philosophic and socio-humanitarian knowledge is presented.

The authors present the implementation results of new interdisciplinary dialogue in the system of socio-humanities and natural sciences within the Zaporizhzhia State Medical University (Ukraine), where the Department of Social Studies has adapted and implemented a number of projects in this area. One of which is the School for Young Lecturers - project in the framework of practice-oriented education.

The article emphasizes that the return of social science to the higher education system and its role in science must be considered as a complex, multi-level process that should be studied and comprehended for its optimal implementation.
\end{abstract}

Keywords: socio-humanitarian knowledge, paradigm, interdisciplinary, transdisciplinary, synthetic methodology.

Introduction

The modern world is rapidly changing, but sometimes being unpredictable in its development and therefore, dangerous. Modern technologies allow us to make large-scale discoveries (for example, in the use of biotechnologies), transform the world around us, but, unfortunately, do not permit us to foresee not only distant outcomes but also immediate consequences of processes being launched.

More and more works regarding the problem of changing the vector of attitude to humanitarian knowledge in the scientific community have appeared in recent decades. However, most of them are general, sometimes rhetorical. Philosophers have always talked about this problem, as, for example, John Horgan (1997) mentioned in his interviews. We would like to refer to several works that are of particular value for our 
study. One of the most interesting and productive researchers for us is Mikhail Epstein (2001, 2004, 2016, 2017, 2019). He is the author of many works in which the problem of a new paradigm of knowledge, the importance of the social and humanitarian sciences and the synthetic methodology of the future science is touched upon. Besides, it is worth noting the works of I. Kasavin (2016), V. Tretko (2013), S. Chechotina (2013), Yu. Lotman (2001) and, especially, V. Porus (2019).

These are the consequences of the positivist paradigm "reign" in both science and education. It is positivism that within a long period of time conveyed A. Comte's (2011) idea that any extrascientific knowledge can affect the development of scientific knowledge rather in terms of quantity than in terms of quality - it can accelerate or slacken scientific process (p. 57). However, at the level of philosophical analysis, G. Hegel showed that any knowledge is based on the preexisting culture, history of dialectical relations between the subject and the object. This dramatically changes the essential meaning of science and knowledge in general, and any knowledge is historical and culturally determined, that is any knowledge is affected by social factors. Therefore, the problems of cognitive communication should be further comprehended in the paradigm of "social philosophy of science" (Kasavin, 2016, p. 222). According to I. Kasavin (2016), in the dynamics of the future, a man should become part of the single system of the modern world ( $p$. 222). Post-modern man is given a constructivist role. The main principle of constructivism is the principle of world cognition by building models, where science and education are the essence of the future. Not without reason, according to UNESCO, the $21^{\text {st }}$ century should become the "Age of Education". Education and science constitute the core of the major resources of the new civilization development stage based on hightech technologies (bio-, nano-, info-, electrochemistry, etc.). The process of constructing the image of the future sets the essence of development, where the leading role belongs to the man, creator with adequate moral beliefs, value orientations and creative abilities.

Today's economy is being transformed, developed into an "intellectual" economy.

Creative, innovative activity, creative abilities of the individual characterized by the ability to produce fundamentally new ideas - all these characterize the concept of creativity. The ability to create something new also allows being aware of the new in existence, to comprehend and feel it. Divergent thinking is one of the most important indicators of modern human wealth.

True human wealth is the ability to create, desire to create something new and improve the existing one, or simply create the same thing in a different way. It should be noted that for this purpose, it is necessary to comprehend the essence of the activity object.

In the process of activity, the main thing for a creative person is not only to create something new, but also to show his creativity, feel this aspiration and implement it. A modern man needs to create something new and be able to adequately evaluate his activities in order to make sure that his actions are creative. In fact, a creative person has a vital need for creation. However, as a subject of activity, with this view, he needs to possess necessary skills and knowledge, which are characterized by the concept of human capital.

In this article, we aim to reveal the main 
cause-and-effect relations that have resulted in modern societies in demand for revival of philosophic and socio-humanitarian knowledge in science and education. We will make an attempt to predict the form of socio-humanities in the near future in the framework of modern education, in particular, focusing on higher medical education.

In the mid-90s of the last century, John Horgan's work "The End of Science" was published, where the author reflects on the fact that science in its "pure form" can no longer exist since all the most important things have already been discovered. There appears an idea that to support scientific progress, more and more effort and resources will be necessary, human resources are limited and not able to infinitely saturate science; therefore, progress cannot last infinitely. "When the questions arise, which science cannot answer, ambitious scientists pursue science in a non-empirical mode that I call ironic science, even after empirical science - science that answers questions - comes to an end" (Horgan, 1997, p. 51).

We will not insist on this standpoint since the problem can hardly be resolved and is purely hypothetical, but it is possible to assume that there is some truth in this idea. If the basic laws of the universe are already known to mankind, the logical question arises - what is next? Most likely, there comes time when the "puzzles" of scientific knowledge are collected many times again, creating, like a kaleidoscope, new pictures of the world, new approaches and, accordingly, new disciplines. "No matter how far empirical science can go, our imagination is always able to go further" (Horgan, 1997, p. 51).

Everyone, who has had anything to do with science over the past (at least) 50 years, has been discussing, participating in and creating interdisciplinary contexts of scientific knowledge. Dis- ciplines presented to the world as a symbiosis of two or more sciences have long been introduced into university programs. However, this process continues and creates new opportunities for combination, the synergy of knowledge obtained in different areas.

Another question arises - who is the conductor of this amazing orchestra of new interdisciplinary areas, which can form and direct these new structures in a most productive way?

There is an attempt to answer these questions made in the writings by Mikhail Epstein, who claims that projectivity is experiencing a rapid rise. What is most interesting is that the things previously considered to be the unchanging reality often become projects.

"Scientists believe that their "birth", or rather a synthesis, will help create a unified theory of physical forces and interactions. Thus, the "objective" theory turns into the "projective" one, that is, it is assumed that the theory should be completed by further practice" (Epstein, 2016, p. 110).

Therefore, social and humanitarian sciences, as well as philosophy, are currently the "methodological regulatory framework for development" of modern society. The philosophical culture of the individual is formed and developed through analysis, criticism of the ideals and norms of the culture of thinking being shaped in everyday life.

The preservation of socio-humanitarian and philosophical disciplines in the educational discourse is an opportunity to form a human worldview as an ontological factor that guides man.

Modern education has not only received a large number of new technological tools, which we should learn to use efficiently, has also become a political, remedial and social technology. Professors of Humanities should take this fact 
into account and use new technologies to avoid the catastrophe of global dehumanization. If social and humanitarian disciplines have an opportunity to profit from impersonal technologies, we should use this opportunity to turn from passive observers and researchers into active creators of a new reality, with the man being the core of it.

The "philosophy of synthesis" project proposed by M. Epstein is so relevant that it enables granting a new innovative status to philosophy and many socio-humanities, delivering them from useless tautology and translation of outdated or subjective political views. According to the author, to this end, it is necessary to reprogram the methodological settings of both philosophy and socio-humanitarian knowledge.

In his article "Philosophy as a Dream of the Future", professor V. Porus expressed some interesting thoughts on this issue with regard to redirecting the methodological setting of philosophy - "from analysis to synthesis". The author points out that the method of synthesis admits a lot of interpretations: from the synthesis of notions to synthesis of philosophical and scientific concepts occurring in the interdisciplinary study of complex, multi-factor processes (Porus, 2019, p. 82).

The issue of synthetic methodology creation that is extremely necessary for the science of our time is quite relevant, since it enables collection and combination of basic components in a new way and, in principle, is the only possible way to study what can/could happen. According to M. Epstein, it is synthetic disciplines that represent not even the immediate future but the concrete present of our science. Scientific community seeks to move from the knowledge of what has already happened to the knowledge of what has not yet occurred (Porus, 2019, p. 85). Accordingly, the research in synthetic sciences can be grounded on a general scientific methodology, which is based on the mechanisms of knowledge integration, interdisciplinarity, transdisciplinarity and polydisciplinarity. We assume that it is expedient to consider the main concepts that define new trends in the development of modern education and science.

According to Vitalii Tretko (2013), a Ukrainian researcher, "Interdisciplinarity" is used in different meanings; "polydisciplinarity" and "transdisciplinarity" are synonyms to this concept with some differences in interpretations (p. 96). Polydisciplinarity means the study of a certain complex object jointly by different disciplines (for example, the study of man by psychology, genetics, sociology, etc.). Here, a possibility of dialogue between sciences is only outlined, with each science having its own subject of research. Transdisciplinarity means that research goes beyond disciplinary limits, and research schemes are transferred from one branch to another. Transdisciplinary research is a collaborative research project for several distinct branches of scientific knowledge. Interdisciplinary interaction involves communication, in which each discipline is both autonomous and open. It is necessary that every scientific discipline included in poly- and transdisciplinary complex should be both open and closed. "It should be open to new cognitive schemes transferred from related and more distant scientific disciplines, which have a heuristic significance for it; it should be ready to cooperate with other scientific disciplines in order to implement joint research projects. However, a scientific discipline should be closed, as it seeks to preserve its specific subject and research perspective, develop progressive and most advanced research methods and strategies" (Tretko, 2013, p. 96).

The term "integration" (from Latin integ- 
rum - complete, integratio - renewal) means combining, interpenetration. This is the process of combining elements (parts) into a single whole, the process of mutual approach and formation of relationships. Interdisciplinary integration is a targeted strengthening of interdisciplinary links in order to maintain the theoretical and practical integrity of academic disciplines (Chechotina, 2013, p. 86).

It is important to determine the field, in which the most exciting scientific "battles" will take place in the near future. We are convinced that this area will be directly and indirectly related to medicine. It is here, in the sciences about the man and for the man, technology and new scientific discoveries will find their new application domain. Thus, it is medicine where the role of the socio-humanitarian and philosophical components is rather significant.

On this "battlefield", we can see that the events related to technization of the man and anthropologization of the machine are already developing. Therefore, it is crucial to consider possible points of contact between socio-humanitarian and philosophical knowledge in medicine that is actively working on the creation of a trans-humanized being, which means that it creates a superhuman, realizes the human desire for self-creation.

Why are socio-humanitarian and philosophical components so important in higher medical education? Let us thoroughly examine the situation.

The ability to invent and create new things is named among the most important skills of humanity, especially active this ability is realized in the 20 and the $21^{\text {st }}$ centuries, and, of course, medicine is the sphere where something new will be created all the time. This is caused by the fact that aspiration for self-creation, self-improve- ment and immortality has always been of great importance and among most desirable for man. In addition, as stated by J. Horgan (1997, p. 22), provided that in the near future science is only developing in the areas where it makes real material profits (that is the reason for investment allocation in research), the field of medicine will never suffer from a lack of funding. People have always been willing to give all their treasures to prolong youth, beauty and health. Therefore, it is so important for the medicine to educate scientists who are able to think critically, approach issues in a non-standard and creative way and invent something new.

Thus, it is obvious that the social and cognitive role of both philosophy and all socio-humanitarianism is changing. In modern conditions, philosophy follows science, art, politics, religion and everyday experience. The socio-philosophic understanding of the modern science nature, in particular medicine, contrasts with the economic dimension image of the scientific and technical complex, in which fundamental knowledge is devalued, and the role of the instrumental science product as a commodity is absolutized. This raises the question of the possibility and necessity of a new social philosophy of science, a new discipline - philosophy of medicine. Thus, the national tradition in teaching philosophy should be restructured.

There are some interesting ideas in this regard presented by professor V. Porus. He declares, "it is time for Philosophy to leave behind the "remedial" functions of clearing the language of science from metaphysical remnants and linguistic traps, which is what "analytical philosophy" is intended for (Porus, 2019, p. 85); actually, it is not philosophy, but that is why it persistently pretends to be one. Such mimicry was justified a hundred years ago when the struggle 
against metaphysics under the banner of "scientific philosophy" was under way. Having built up their muscles in this struggle, the institutions of "analytical philosophy" have gradually acquired such impressive dimensions that they are currently said to be "predominant" in the modern philosophical world. Although there seems to be no one to fight against, and since the old metaphysics is still seen only in historical and philosophical obituaries, these institutions preserve their fighting spirit and are ready to fight against windmills. Taking care of ammunition, philosophical analytics surrounds itself with special filters and scientific criteria. "Its texts are full of references to logical-mathematical and logicalsemantic results, which provides them with certain respectability and inspires confidence - in contrast to speculations, which make people, who are trained to "do things" rather than chase after some philosophical wind, sick and tired. A masquerade can last long, but not forever. Even today, it is clear that analytical studies do not have a noticeable impact on processes in science (both in natural science and humanities) as well as on the "rest" of cultural life. Rare exceptions prove the rule" (Porus, 2019, p. 87).

It is not possible to disagree with these thoughts. Hegel (1932) wrote that the owl of Minerva flies only at dusk, but dusk is not eternal, there is a hope for dawn to come: having "woken up" in the morning, humans will draw conclusions and "learn from errors" (p. 103). However, under modern terms of "death of the social", "simulation will only be defeated by simulation" (Baudrillard, 1983, p. 78); therefore, we need to act immediately. In a particular case, it is necessary to help philosophy out of the marginality and adapt it to the conditions of Medical University within the framework of the interdisciplinary paradigm.
What exactly should be taken into account in higher education in the first place in order to meet the basic needs of the future? Here, we should consider several points on the example of higher medical education, namely, education at the Zaporizhzhia State Medical University (ZSMU). It is appropriate to reveal the two main areas through which ZSMU is actively involved in the global network of higher medical education players, who are learning to quickly and productively respond to the challenges of today. We are not only moving from one paradigm of university development to another, we are also observing a large diversification of university models and must create this new reality together. Part of this new educational reality, the authors of which are a creative tandem of university management and lecturers of Humanities departments, consists of, firstly, online courses that ensure implementation of new educational projects of the global educational space, which are essential for a modern higher education institution; and, secondly, practice-oriented education, adult education.

The problem of training specialists, who are ready to develop the synthetic methodology and create inter-, trans-, meta-paradigm disciplinarity, is a separate issue. Like nuggets, this kind of specialists cannot often appear in the background of the old scientific paradigm. They need to be educated in comfortable conditions and taught the basic principles of nonlinearity. "You need to know a lot about the things that exist in order to create something unprecedented. At the same time, you need to create something unprecedented in order to better understand the things that exist" (Epstein, 2016, p. 112). Computer simulations are actively used in medical education and science, creating new models of reality that require researchers seeking new regularities. 
"Nowadays, due to innovative technologies, we are leaving the universe for the multiverse - the era of multi-dimensionality, when virtual universes begin to multiply, gaining more and more material authenticity" (Epstein, 2016, p. 112). With the view of this, the system of postgraduate medical education, which trains Doctors of Philosophy, is developing new programs which enable moving away from the ordinary education paradigm. Professors of philosophy are responsible for creating a new type of scientist able to abandon the clichés and standard constructs of science.

To satisfy the demands, the Zaporizhzhia State Medical University introduced the institute of mentoring under the School for Young Lecturers project in the framework of practiceoriented education, rightfully declaring that this is the only project in the Ukrainian higher medical education (in the context of a general reduction in humanitarian education and deprivation of its humanistic component, our University pays great attention to the training of talented lecturers).

University young scientists are in the centre of events, ready to work in modern, often paradoxical conditions: a lack of time and money, an abundance of information, etc. There is no doubt that in Ukrainian universities there are disciplines that provide post-graduate students with a common understanding of pedagogical activities, but they become aware of the need for such knowledge only on entering a lecture hall (from the preparation of lectures and practical training to conflict situations emerging in the classroom). This is when there is a vital need for help, obtaining necessary information fast and, in general, support and advice from their mentor. This objective reality resulted in a progressive management decision to introduce the School for Young
Lecturers project. The Department of Social Studies and the Department of Cultural Studies and Ukrainian Studies were entrusted with the task of realization and implementation of this project, from the development of a unique (in the system of higher medical education) program to holding masterclasses in the framework of meetings with colleagues.

In order to form the pedagogical skills of young teachers, exclusively applied materials were selected: from a social and philosophical discourse to a psychological and pedagogical one. All the materials and the entire project aim to create new "social skills", which are also referred to as "soft skills" ("social skills", "universal skills" or "success skills"). "Soft skills" is a complex of non-specialized, highly professional skills vital for successful participation in work performance and high productivity. They allow post-graduate students to perform efficiently at their workplace. Soft skills include communication skills, leadership, abilities to take responsibility and work under pressure, settle conflicts, work in a team, manage their time, understand the importance of deadlines, think logically and systematically as well as creativity, etc.

Therefore, the following methodological forms were used: training, business games, case studies. The lectures and workshops provide the necessary information in three modules, which include specific topics namely: 1) Logical and Philosophical Workshop on Rhetorical and Communication Competence; 2) Psychologicalpedagogical and Methodological Training of Young Lecturers; 3) Conflictology in Modern Higher Education. Development of Creative Thinking. We should note the following classes among those included in the above-mentioned training modules: "Logical Foundations of Argumentation", "Features and Techniques of Ora- 
tory. Rhetorical Devices for Speakers", "Forms of Speech Communication (dialogue, monologue). Dispute as a Type of Speech Communication. Strategy and Tactics of Argumentation". Practical training sessions in the determination of the psychological and typological communication characteristics of a young teacher's personality and a workshop on the culture of professional speech are included in the above modules as well: "Speech and Communication Training", "Personality and the Masses: Peculiarities of Behaviour in the Context of Higher Education. Social Psychology to Assist Organization of Interaction between the Teacher and the Student", "Peculiarities of University Education in the Context of Globalization. Dialogue of Philosophy and Science in Western and Eastern Cultures", etc.

The worth of personality, professional qualifications and man's individual characteristics character, intuition, ability to choose search strategies, even zest for life - all these affect a young teacher in selecting a model of reality, first of all, a professional one. This is the kind of professional to be trained by a modern University, and this is the kind of professional to work in modern University. Such kind of professional is the greatest social value; therefore, social and humanitarian disciplines headed by Philosophy should always remain the basis for his/her training.

\section{Conclusions}

Socio-humanities and philosophy today is a "methodological regulation" of development for modern society. The philosophical culture of the individual, which forming and developing through analytics, critique of ideals, norms of the culture of thinking, acts as a regulation for sci- ence and education. The preservation of the socio-humanitarian, philosophical disciplines in the educational discourse allows us to form an adequate worldview that will correspond to the specific cultural and historical system in which the person is located. Besides, modern education has not only received a large number of new technological tools that it must learn to use with optimal results - it becomes a political, therapeutic, social technology.

We attempted to justify the need to redirect the methodological installation of philosophy from analysis to synthesis. An example of the creation and application of the synthetic methodology in the field of higher medical education is presented. To satisfy the demands of forming and use of such methodology, Zaporizhzhia State Medical University introduced the institute of mentoring under the School for Young Lecturers project in the framework of practice-oriented education, rightfully declaring that this is the only project in the Ukrainian higher medical education.

Thus, the return of socio-humanities to the higher education system and their role in science must be considered as a complex, multi-level process that should be studied and comprehended for its optimal implementation. It is very important to save this process from a cynical desire to reduce, vulgarize and diminish the significance of socio-humanities in modern science. Otherwise, the "prosthetic style" will result in tragic consequences and post-humanism will become a sad reality, in which nothing can be changed to return to humanity.

\section{REFERENCES}

Baudrillard, J. (1983). Simulations. Los Angeles, California: Semiotext. 
Chechotina, S. (2013). Aktualnist uprovadzhennia mizhdystsyplinarnoi intehratsii pry vyvchenni farmakolohii (The Relevance of Interdisciplinary Integration in the Study of Pharmacology, in Ukrainian). Ukrainian Dental Almanac, 4, 86-88.

Comte, A. (2011). Dukh pozitivnoi filosofii (The Spirit of Positive Philosophy, in Russian). Moscow: Izd-vo Librokom.

Epstein, M. (2001). Filosofiya vozmozhnogo. Modal'nosti v myshlenii i kul'ture (The Philosophy of the Possible: The Modalities in Thought and Culture, in Russian). Saint Petersburg: Aleteia.

Epstein, M. (2004). Znak probela: O budushchem gumanitarnykh nauk (Mapping Blank Spaces: On the Future of the Humanities, in Russian). Moscow: Novoe literaturnoe obozrenie.

Epstein, M. (2016). Ot znaniya - $k$ tvorchestvu. Kak gumanitarnye nauki mogut izmenit' mir (From Knowledge - to Creativity. How the Humanities Can Change the World, in Russian). Moscow, St. Petersburg: Tsentr gumanitarnykh initsiativ.

Epstein, M. (2017). Proektivnyi slovar' gumanitarnykh nauk (The Projective Dictionary of Humanistic Disciplines, in Russian). Moscow: Novoe literaturnoe obozrenie.

Epstein, M. (2019). Budushchee gumanitarnykh nauk: Tekhnogumanizm, kreatorika, erotologiya, elektronnaya filologiya $i$ drugie nauki XXI veka. (The Future of the Humanities: Technohumanism,
Creatorics, Erotology, Digital Philology and Other Disciplines of the XXI century, in Russian). Moscow: Ripol-klassik.

Hegel, G. (1932). Lektsii po istorii filosofii (Lectures on the History of Philosophy, in Russian). Moscow: Partijnoe izdatel'stvo.

Horgan, J. (1997). The End of Science: Facing the Limits of Knowledge in the Twilight of the Scientific Age. New York: Broadway Books.

Kasavin, I. (2016). Sotsial'naya filosofiya nauki i kollektivnaya epistemologiya (Social Philosophy of Science and Collective Epistemology, in Russian). Moscow: Ves Mir Publishing House.

Lotman, Yu. M. (2001). Semiosfera. Kul'tura i vzryv. Sredi myslyashchikh mirov (Semiosphere. Culture and Explosion. Among the Thinking Worlds, in Russian). Saint Petersburg: Iskusstvo SPB.

Porus, V. (2019). Filosofiya kak mechta o budushchem (Philosophy as a Dream of the Future, in Russian). Voprosy Filosofii, 7, 82-88. doi: 10.31857/S004287440005729-6.

Tretko, V. (2013). Mizhdystsyplinarnyi pidkhid u pidhotovtsi maibutnikh mahistriv mizhnarodnykh vidnosyn (Interdisciplinary Approach in Training Future Masters of International Relations, in Ukrainian). Osvita doroslykh: teoriia, dosvid, perspektyvy, 6, 94-103. 